\title{
The Utility of Fusion Centers to Enhance Intelligence-Led Policing: An Exploration of End-Users
}

\author{
Carla Lewandowski \\ Rowan University \\ lewandowskic@rowan.edu \\ Jeremy G. Carter \\ Indiana University - Purdue University Indianapolis \\ Walter L. Campbell \\ Rutgers University
}

\begin{abstract}
A developing literature on intelligence-led policing (ILP) and law enforcement fusion centers contends that intelligence and data-driven policing practices can be enhanced through improved intelligence dissemination from fusion centers. The literature has remained relatively silent on the extent to which law enforcement has connectivity with fusion centers, perceive fusion center products to be useful, and further share intelligence products within their agency. The present study informs this knowledge gap using data gathered via an online survey of law enforcement subscribed to receive fusion center products. Bivariate logistic regression models showed that rural agencies tend to be the most informed about the fusion center of study while a disconnect was observed between the fusion center with respect to frontline personnel and analysts; especially in urban police, health, and fire organizations. Implications for research and practice are discussed.
\end{abstract}

This is the author's manuscript of the article published in final edited form as:

Lewandowski, C., Carter, J. G., \& Campbell, W. L. (2018). The Utility of Fusion Centres to Enhance IntelligenceLed Policing: An Exploration of End-Users. Policing: A Journal of Policy and Practice, 12(2), 177-193. 


\section{Introduction}

The turn of the century saw a shift in American policing from a mostly reactive force to one that attempts to use data and intelligence in an effort to be proactive. One such philosophy, known as intelligence-led policing (ILP), is a relatively new policing practice that has gained operational momentum with sparse empirical assessment (Carter et al., 2014). Though ILP existed prior to the attacks of September 11, 2001 (9/11), most notably in the United Kingdom, the attacks of 9/11 served as the catalyst for ILP's emergence among law enforcement in the United States. With the introduction of new technology and the use of law enforcement data, it has now become the means through which police seek to tackle complex crime problems such as street gangs (Ratcliffe et al., 2015) and violence reduction (Bureau of Justice Assistance, 2012). Though ILP originated as a strategy to combat complex criminality, such as terrorism and organized crime, the information sharing and analytic tenants of ILP are applicable to many of the problems police face; akin to a more robust problem-oriented policing strategy.

Further, a problem-oriented approach (Goldstein, 1979) coupled with an emphasis on intelligence related to habitual offenders has been shown to be a promising strategy to reduce crime in hotspots (Groff et al., 2015). Despite this importance, many municipal agencies lack the internal capacity to produce meaningful analyses or are unaware of available access to this capability (Cooney et al. 2011; Lewandowski \& Carter, 2014; Riley et al., 2005). State and regional (also known as major urban area) fusion centers were developed as a means to facilitate ILP among local agencies. More specifically, regional fusion centers with their restricted geographical focus are in a strategic position to bridge information and resources to understand multijurisdictional crime problems (Carter, 2015). 
For purposes of context it is important to note that fusion centers ${ }^{1}$ were developed to serve as a single point of contact for crime, terrorism and threat-related information to be received, analyzed, and disseminated to improve situational and operational awareness (Fusion Center Guidelines, 2006; Global Intelligence Working Group, 2005; U.S. Department of Homeland Security, 2005). The decentralized American policing system makes a fusion center necessary to help police agencies communicate. However, over time fusion centers have evolved from their terrorism-centric mission to a broader "all-threats, all-crimes, all-hazards" approach to public safety (U.S. Department of Homeland Security, 2015). This evolution to include crime data coupled with the geographic presence of fusion centers within every state, and in some cases multiple centers per-state, has positioned fusion centers to enhance the analytic capacity of local law enforcement. However, the degree to which fusion centers are able to provide this analytic assistance remains elusive and is the focus of the present study.

\section{Purpose of the Study}

Fusion centers are a means through which local police agencies can engage in ILP. As previously noted, many agencies lack an in-house analytic capacity that is capable of informing tactical and strategic decision making to combat crime and threats to the community. Put simply, local agencies that receive analytic products from fusion centers may be able to leverage such products to become more intelligence-led. Salient to the present study is the intelligence and information sharing process - also known as the intelligence cycle. Though components of this cycle vary, common processes include

\footnotetext{
${ }^{1}$ When not explicitly stated, fusion center is used as a general term to denote all fusion centers, both state and regional.
} 
collection and analysis of information to create intelligence, dissemination and sharing of intelligence, and evaluation and utility of intelligence to information actionable outcomes (Carter and Carter, 2009; Ratcliffe, 2016). Fusion centers play a central role in the former components of this process as their mission is to collect, analyze, and disseminate information and intelligence. Moreover, the sharing of information is not, and should not, be limited to a flow from a fusion center to local agencies. End-user recipients should further share this information both within their own agencies as well as with other organizations believed to benefit from the intelligence.

While the latter component - how intelligence is utilized to develop actionable outcomes - is perhaps the most important aspect of ILP, it is not the focus of the present study for three primary reasons. First, outcomes that result from an ILP approach are elusive and highly subjective to agency-specific missions and goals (Carter, Phillips, \& Gayadeen, 2014). Second, prior to any occurrence of outcomes from ILP and in order for intelligence to be utilized by local agencies it must first be analyzed and disseminated. In order for fusion centers to share intelligence products with local agencies there must exist connectivity between these organizations (i.e., agencies must be both aware of the fusion center and subscribed to their dissemination list). Third, this process of receiving and sharing intelligence among end-users of a fusion center has gone largely ignored in the literature. Thus, this is the current state of the fusion center - ILP science and requires scholarly attention. Hence the focal point of the present study to examine end-user perceptions of connectivity with a fusion center and the extent to which analytic products are received and shared to enable an intelligence-led approach among local agencies. 
Research examining the function of crime and intelligence analysts within law enforcement agencies suggests a lack of communication between analysts and end-users of analytic products (Cope, 2004; Santos, 2014; Taylor et al., 2007). It is important to note that disconnect between analysis and subsequent police action is far more complex than simply a lack of communication. Both Sanders, Weston, and Schott (2015) and Cope (2004) found cultural differences between analysts, police officers, and administrators as these different groups of personnel exhibited different beliefs with respect to the role of information, intelligence, and analysis. For example, administrators view analysis as a means to bring credibility, management, and accountability to the agency whereas officers desire to receive information to assist their crime reduction and prevention mission and are more hesitant to provide information they believe is important to their success in this effort. Similarly, Sheptycki (2004) noted that detectives were primarily interested in information that would facilitate arrest and prosecution, not trends or patterns of criminality. Such nuances are salient to understanding how intelligence and analysis are utilized in police agencies, but are outside the scope of the present study. It is worth reinforcing the point that before information, intelligence, and analytic processes can be leveraged by agencies, they must first have access to an analytic capability and receive information and intelligence.

Specific to all fusion centers and ILP, research has demonstrated a gap between fusion centers and local law enforcement agencies, studies of which have been informed through interviews with fusion center personnel (Graphia-Joyal, 2010; Lewandowski \& Carter, 2014; Ratcliffe \& Walden, 2010). A critical aspect of this disconnect is the extent to which end-users of analytic products receive, review, further disseminate, and perceive 
utility of analytic products they receive. In the present study, an end-user is defined as the person who receives the e-mailed analytic products from the fusion center. The degree to which such end-users perceive and/or utilize such products has received scant scholarly attention and is the focal point of the present study.

Prior research (Graphia-Joyal, 2010; Lewandowski \& Carter, 2014; Ratcliffe \& Walden, 2010) suggests end-users opt to receive intelligence products as they are expected to assist in some form of decision making or strategic benefit. This assumption, or expectation of analytic products, among end-users has not been explored. To this end, the present research utilizes a survey of one regional fusion center's end-users to quantify enduser perceptions of analytic products across a range of metrics of interest. Through descriptive and bivariate analyses the results provide unique and insightful findings that speak to the disconnect observed in previous research. These findings have implications

for policy and practice by improving intelligence dissemination through tailored analytic products, fusion center outreach, and enhanced relationship fostering. Recommendations for future research are provided to guide social inquiry to refine the use of crime and intelligence analysis to impact practice.

\section{Literature Review}

Currently there exist 53 state and 25 regional, or major urban area, fusion centers across the country; each center is designed to cover a specific geographic area connecting local, state, and federal law enforcement, emergency services, transportation services, and a wide 
variety of private businesses within that area (Carter \& Carter, 2009). Generally speaking, the mission ${ }^{2}$ of fusion centers is to:

“...contribute to the Information Sharing Environment (ISE) through their role in receiving threat information from the federal government; analyzing that information in the context of their local environment; disseminating that information to local agencies...They analyze the information and develop relevant products to disseminate to their customers. Beyond serving as a focal point for information sharing, fusion centers add significant value to their customers by providing a state and local context to help enhance the national threat picture" (U.S. Department of Homeland Security, 2016, n.p.).

While state fusion centers are generally operated and staffed by the state police, regional fusion centers are authorized by federal authorities and may be managed by a local police department or another federal entity such as a HIDTA. Thus regional centers may have noticeably different goals and styles of leadership than state fusion centers. Moreover, because perceived similarity is associated with increased information sharing between departments (Roberts \& Roberts, 2007; Weisss, 1998) and police officers with a similar position in a nearby geographic area (Lewandowski \& Nestel, 2016), it is logical to assume that regional fusion centers which are managed by those within their region, are uniquely positioned to enhance intelligence-led policing and data-driven police strategies because local police officers may share information more readily with their colleagues in the regional fusion center. This perspective is consistent with peer emulation principles of institutional theory that have been found to facilitate crime analysis (Giblin, 2006) and ILP (Carter, 2016). In addition to being more willing to send information and give feedback to

\footnotetext{
${ }^{2}$ There exists a high degree of variability with respect to the structure, capacity, and operations of each fusion center. Additional information pertaining to the nuances of the National Network of Fusion Centers can be reviewed within the 2015 performance report published by the U.S. Department of Homeland Security at https://www.dhs.gov/sites/default/files/publications/2015\%20Final\%20Report\%20Section\%20508\%20Co mpliant.pdf
} 
the regional fusion center, the local police officers may place more value in products that were produced by analysts who they perceive to have a better understanding of the issues they face. It is important to note that not all regional fusion centers are managed by their local police department and indeed, state fusion centers may have liaisons from local police departments embedded in their centers.

\section{Fusion Centers to Facilitate Intelligence-Led Policing}

Research to date has explored a number of fusion center characteristics spanning information sharing practices, relationships, and analytic functions. Such works have informed the academic understanding of these new organizations, but also have contextualized these functions as a component of local ILP efforts. Several studies have demonstrated that fusion centers have improved law enforcement information and intelligence sharing consistent with federal recommendations (Carter, 2015; Carter \& Chermak, 2012; Chermak et al. 2013; Ratcliffe \& Walden, 2010; U.S. Governmental Accountability Office, 2010; U.S. House of Representatives, 2013). While informative, each of these studies utilized data from fusion center personnel and did not include observations from organizations that partner with, or receive intelligence from, fusion centers. These end-users are personnel and agencies that rely upon analytic products to help inform operational, situational, and strategic decision making. Even in cases where an agency may have an internal analytic capability, fusion center products likely include a broader perspective of relevant data (Carter \& Chermak, 2012).

Studies sampling fusion center end-users have provided mixed findings. In their surveys of fusion center end-users, both Cooney et al. (2011) and Lewandowski and Carter 
(2014) found low levels of satisfaction among end-users with fusion centers and limited utility of intelligence products they received. With respect to how fusion centers facilitate ILP for local agencies, Carter (2015) found that less than 17 percent of the law enforcement from a national survey reported that fusion center products provided content to aid in the prevention of crime. Cooney et al. (2011) observed more promising results that a state fusion center was able to provide analytical support for local agencies that wished to implement ILP and lacked the necessary resources to do so on their own. This finding has been echoed by others examining state fusion center ender-users (Lewandowski and Carter, 2014; Ratcliffe \& Walden, 2010) and is consistent with research findings that smaller agencies are less likely to employ an intelligence analyst (Riley et al., 2005) or be aware of threats in their jurisdiction (Buruss et al., 2010).

Perhaps the lone finding gaining consensus in fusion center research is that fusion centers have acknowledged a desire to market their capabilities to local law enforcement agencies while local law enforcement, relatedly, has indicated ambiguity regarding the mission of fusion centers. Graphia-Joyal's (2010) 49 interviews with fusion center personnel at four state fusion centers revealed that personnel perceived the center to not yet be part of the larger law enforcement community, and "thus their potential value is neither fully acknowledged nor drawn upon" (p.69). Scholars have also found this to be true internationally. Innes, Fielding and Cope (2005) found that the intelligence centers in the UK were merely repackaging policing data and information rather than using an analytic process with any true scientific application. This may be attributed to the agencies' place in the organizational hierarchy of government and thus different operational 'scope' 
(Ratcliffe, 2007) or perhaps reflect differences in training, exposure, or analytical approach (Ratcliffe, Strang, \&Taylor, 2014).

Subsequent studies reiterated the need for fusion centers to notify their current and potential stakeholders of their analytic services (Chermak et al., 2013; Graphia-Joyal, 2010) and data availability (Carter \& Chermak, 2012). This may be due to the confusion in objectives among fusion centers and its users. While most fusion centers expect and intend to collect and analyze information that has been "pushed" to them, a term used by Ratcliffe (2016) in his 3-I model of intelligence-led policing, evidence from studies of endusers reveals that many end-users want more of a support service from their local fusion center (Cooney, et al., 2007; Lewandowski and Carter, 2014; Ratcliffe \& Walden, 2010). However, studies abroad (Darroch \& Mazzerole, 2013) and more locally (Ratcliffe \& Guidetti, 2008) have found that leadership may also need to encourage the practice of ILP within their own agencies.

\section{Gaps in the Fusion Center Literature}

A review of the research reveals noticeable knowledge gaps. With respect to information sharing, there are two ways for information and intelligence to diffuse. First, agencies have to connect to the fusion center. In other words, agencies need to be aware of the fusion center and then understand how to obtain information. Second, analytic products must diffuse, or information must be shared beyond the initial point of contact. Fusion centers disseminate information and intelligence but many fusion center personnel are unaware of what is done with the information once it is disseminated. It remains unknown if local, state or federal law enforcement agencies read it, whether they find it useful, or if it fulfills 
their analytic needs. These end-user factors have received minor scholarly attention (Lewandowski \& Carter, 2014).

Moreover, there has been no research to date that has explored the experiences of regional fusion center end-users or a regional fusion center's ability to enhance ILP and data utilization. Regional fusion centers have notable differences from state centers. Regional centers are not only closer in proximity to their constituents due to the designated major urban area of responsibility, but many regional fusion centers are managed and/or staffed by a large municipal police department to whom other local police departments may be able to more easily relate. Local police officers assigned to a regional fusion center have not only worked on local crime, as opposed to patrolling highways as is the case for state police who often run state fusion centers, but they have often built a network of contacts across the immediate geography they can utilize for information and a knowledge of local policing needs. Such unique location and specialized knowledge is likely to facilitate ILP and emerging data-led strategies such as hotspots policing. Lastly, the literature has yet to identify the operational focus of end-users and their actions once they receive intelligence.

Intelligence needs of non-law enforcement agency end-users differ from those of law enforcement agency end-users. Personnel in the private sector, health, and emergency management fields have varied needs, in addition to security levels, from those of law enforcement personnel.

\section{Methods}

The present study was conducted at a regional fusion center and is designated as a "Recognized Fusion Center" by the U.S. Department of Homeland Security. A recent 
report by the U.S. Department of Homeland Security (2014) documented the organizational capabilities and practices of each fusion center nationwide and quantified operational scores for each center across a range of metrics. Based on these metrics, the fusion center studied herein received an "average" rating compared to centers across the country. While there is no single model for a fusion center (Rollins, 2008), a rating that suggests the center of study has operations and practices similar to those nationwide helps to enhance the generalizability of the findings, despite issues with non-response bias presented below.

End-user information was gathered via a 31-item online survey consisting of Likertscales as well as open and closed-ended questions. The sample of end-users was derived from the fusion center's intelligence dissemination listserv which were organized by type of organization, level of government, geographical location, and whether the agencies are private or public. Subscribers to this listserv regularly receive an analytic product similar to a common operating picture (COP). Contents of the COP vary dependent on observed crime trends, emerging criminality, threats, and even large events. Though contents of the COP can vary, the intelligence and information included is always the result of an analytic process to collate and synthesize information for recipients. The survey was disseminated to all 1,576 listserv recipients. Persons receiving the request to participate were asked to complete the survey on behalf of their organization. This led to a robust and varied sample of end-users representing an array of public and private organizations at various levels of government and within varied geographical contexts. The survey was distributed in March 2014 with six subsequent requests for participation and concluded in April 2015. For each sampling request, respondents who had already completed the survey or those who asked to be removed from the study were removed from subsequent requests. 
The final sample was comprised of 339 agency responses, resulting in a response rate of 21 percent. Though not ideal, this response rate is not surprising as online surveys yield lower response rates than other sampling methods (Shih \& Fan, 2009) and crosssectional response rates in social sciences are declining (Brick \& Williams, 2013). This response rate is also consistent with other surveys conducted with intelligence and fusion center personnel (Carter, 2015; Chermak et al., 2013). The research team requested detailed information on listserv (sample) recipients in an effort to examine potential nonresponse biases, however this request was denied due to security concerns. However, the research team was able to compare proportions of respondents in the sample to those of the entire listserv. These comparisons revealed no noticeable differences across law enforcement type (federal, state and local) and non-law enforcement organizations (health, fire, private sector, emergency management).

Sample descriptives are reported in Table 1. In terms of position, respondents were predominately upper level personnel $(42.2 \%)$, followed by mid-level personnel $(25.2 \%)$, frontline personnel (15.0\%), and analysts (8.5\%). While the majority of respondents were from law enforcement agencies $(63.7 \%)$, the present study collected data on a sizable portion of non-law enforcement agencies, including private sector agencies (12.1\%), health, fire, and EMS agencies (8.0\%), and emergency management agencies (7.1\%). Among law enforcement end-users a majority were from local agencies (73.2\%), with a handful of respondents from state (8.8\%) and federal agencies (9.3\%). Previous research suggests it is logical to assume regional fusion centers may have stronger local agency contacts (Roberts \& Roberts, 2007; Weiss, 1998; Lewandowski \& Nestel, 2016) as they are operated by municipal agencies. Lastly, more local agencies were urban than rural or 
suburban, with proportions around two-thirds urban and one-third rural/suburban. Despite having an urban area as their core geographical focus, it appears that this regional fusion center also serves a substantial portion of rural and suburban agencies.

\section{[ Table 1 Approximately Here ]}

\section{Analytic Strategy}

This variety in the end-user population allows for comparison across groups to help contextualize the needs of the varied agencies that fusion centers serve. In order to quantify the different experiences of end-users by their position, departmental focus, level of government, and departmental setting, bivariate logistic regressions were run with a dummy variable signifying membership in each group as the independent variable and a dummy variable signifying an affirmative answer to each question as the dependent variable. While multivariate logistic regressions would allow identification of the effects with potential sources of spuriousness removed, sampling design and sample size restrictions do not permit such tests. Specifically, the private nature of the fusion center limited the authors' ability to obtain a random sample of end-users. With this in mind, these findings should be taken as the results of an exploratory analysis, highlighting corollary relationships. Yet bivariate logistic regressions still allow for the identification of predictive relationships. Bivariate and multicollinearity diagnostics were conducted, and no issues were discovered, with variance inflation factors within acceptable levels. The results are not presented due to space considerations, but are available upon request. In 
order to ease interpretation, odds ratios are presented alongside coefficients. All statistical analyses were conducted using Stata (ICv14.1).

\section{Findings}

\section{End-user Connectivity}

Existing connections to fusion centers and involvement in the intelligence process may enhance an agency's use of the center of study and its products (Cooney, et al., 2011). Further, they may suggest deficits in the end-user population's access to intelligence that a regional fusion center can remedy. The intelligence process relies on numerous, active links both within and outside of law enforcement, and a regional fusion center can help create those links (Saari, 2010). For these reasons, it is important to understand how connected the end-user population is to fusion centers generally. The first two columns of Table 2 address this issue by asking whether end-users were aware of fusion centers prior to learning about the fusion center being studied and whether they receive intelligence products from other fusion centers. Table 2 presents the mean and, in parentheses, the standard deviation for each group, which provides a sense of the proportion in each group that answered affirmatively to each question. Following this, the odds ratio is presented in brackets along with the coefficient and an indication of statistical significance from the bivariate logistic regression in order to provide a sense of the predictive power of group membership. Results follow a similar presentation in all subsequent tables, except for Table 3.

\section{[ Table 2 Approximately Here ]}


While there are no strong or statistically significant differences for various positions, there are a few noteworthy patterns for departmental focus, level of government, and departmental setting. Being an end-user from a health, fire, and EMS agency results in a statistically significant reduction in the likelihood of knowing about fusion centers before (64\% less likely) and receiving products from other fusion centers ( $78 \%$ less likely). Health, fire, and EMS end-users are far less connected to fusion centers than any other respondents. Alternatively, respondents from law enforcement agencies appear to be more connected, particularly in terms of receiving products from other fusion centers, for which law enforcement agencies end-users are 77 percent more likely. Among law enforcement, federal and state agencies have a greater likelihood of being connected to fusion centers, with federal agencies being more than eight-times more likely than non-federal agencies of receiving products from other fusion centers. Interesting differences exist between urban and rural/suburban local agencies, as well, as rural/suburban agencies have a higher likelihood of being connected to other fusion centers ( $276 \%$ more likely). This may be because urban agencies have greater access to in-house intelligence products, whereas smaller rural and suburban agencies with fewer resources, must seek them out.

In order to understand whether this regional fusion center helps fill gaps in connectivity to other fusion centers, connectivity to the center of study is assessed in the third and fourth column of Table 2, which measure familiarity with fusion center resources and knowledge of how to contact the center. Generally speaking, nearly a fifth of respondents do not know how to contact the center, and over a third are not familiar with its resources. This confirms previous findings that fusion centers need to do a better job of 
marketing themselves (Carter \& Chermak, 2012; Graphia-Joyal 2010). Yet among groups, levels of connectivity vary widely.

The center of study appears to be successful in reaching out to upper-level managers, who are 80 percent more likely to be familiar with their resources, but does a poor job of reaching frontline personnel ( $46 \%$ less likely) and analysts ( $66 \%$ less likely). The latter is surprising, as analysts work with intelligence on a daily basis, and thus fusion center connections with analysts should be a priority. Among different departmental focuses, law enforcement appear to be most familiar with the center of study, and emergency management agencies have a lesser likelihood of being familiar with resources (58\% less) and knowing how to contact the center ( $64 \%$ less). Again, this is notable because emergency management agencies attend to the sorts of hazardous situations with which fusion centers were designed to assist. Graphia-Joyal (2010) found differences by level of government, with federal and state agencies being more involved than local agencies, and, while not statistically significant, the results presented in Table 2 follow this pattern. Among local agencies, the center of study appears to struggle reaching urban agencies, with 70 percent less likelihood of familiarity and 65 percent less likelihood of knowing how to contact this center. As a regional fusion center is tasked with an area of operation that encompasses a greater metropolitan area, poor outreach to local urban agencies could create substantial gaps in the intelligence cycle, making their products far less effective. Further, the local agencies sample has the lowest connections to other fusion centers; respondents from urban agencies appear to be particularly disconnected from fusion centers when compared to other law enforcement agencies. 


\section{Awareness of Fusion Center}

In order to increase connectivity to key populations of end-users, fusion centers must know how best to reach those populations. Presenting means and standard deviations, Table 3 illustrates how end-users within each group became aware of the center of study. These proportions of past awareness suggest ways in which regional fusion centers may reach groups crucial to their mission and groups that Table 2 highlighted as lacking in fusion center connectivity. Results presented in Table 2 appear to demonstrate that frontline personnel and analysts are particularly disconnected from the center of study, and Table 3 suggests that the best ways to reach these two groups differ. While frontline personnel are most likely to find out via word of mouth (27\%), analysts are most likely to find out via training events $(24 \%)$.

Notably, training events are also the best way to reach health, fire, and EMS endusers, suggesting, as past research has (Cooney, et al., 2011), that training events may be particularly helpful with fusion center outreach. For all departmental types, the Department of Homeland Security (DHS) is also a helpful resource for making connections, but this is especially true for private sector agencies. Table 2 also highlighted the lack of fusion center connectivity to local law enforcement, and while DHS helps connect this center to state $(50 \%)$ and federal (45\%) end-users, it is notably poor at connecting with local agency endusers $(9 \%)$. Instead, work listservs (23\%), word of mouth (24\%), and, once again, training events $(22 \%)$ appear to be much more effective. As urban and local end-users showed lower likelihoods of connectivity, it is worth noting that training events (20\%) and word of mouth $(25 \%)$ are the most effective ways of reaching these agencies. 


\section{[ Table 3 Approximately Here ]}

These mean differences of discovering the center of study suggest outreach strategies. For example, DHS appears to be an effective outreach tool, but mainly for federal and state agencies and private sector organizations. On the other hand, training events seem to be more successful for gaining greater access to end-users from urban agencies, health, fire, and EMS organizations, and end-users whose primary role is as an analyst. The different ways in which different groups access the center of study suggest that fusion centers cannot take a one-size fits all approach to outreach, and as some groups seem to currently have poor connections with the center of study, it would serve the center well to plan its outreach around methods that are most likely to reach those groups.

\section{End-User dissemination of fusion center products}

A complete intelligence cycle does not just rely on connections between organizations, but also on the active sharing of intelligence products. Table 4 reports how various groups share the intelligence they receive from the center of study. The first three columns capture ways in which agencies share products internally, and the fourth how likely they are to share the product either internally or externally. Respondents were allowed to indicate multiple ways of sharing information internally, and overall, the most common way was that all members of the department are made aware of the information (48.1\%), followed by investigative personnel being made aware of the information (44.5\%), and patrol personnel being made aware of the information (41.9\%). Yet more interesting are the differences across groups. Perhaps not surprising, law enforcement are 
more likely to share information with patrol or investigative personnel, while private sector, emergency management, and health, fire, and EMS end-users are noticeably less likely to share information with investigative personnel. This is not surprising as such agencies are likely to have fewer investigative personnel, but what is surprising is that they are less likely to share information with others in their organization as compared to law enforcement. This may reflect that within non-law enforcement organizations information is used by upper and middle management rather than shared broadly with all personnel, and thus to better reach non-law enforcement organizations fusion centers may benefit from creating their products to specifically address an upper and middle management audience. This is bolstered by the findings which do not indicate any substantial difference in whether respondents forward products. It appears that non-law enforcement organizations are not less likely to disseminate products, but that they simply disseminate them in a different manner than their policing counterparts.

\section{[ Table 4 Approximately Here ]}

Within law enforcement, no level of government is more or less likely to forward products, but federal agencies are 56 percent less likely to forward products to all personnel, and instead forward them mostly to investigative personnel. Alternatively, local agencies are 50 percent less likely to forward them to investigative personnel, and instead forward them to all personnel. Among local agencies, the odds that respondents from urban agencies will forward products are quite low. Within law enforcement, the ways in which information is disseminated varies by level of government, and thus those writing fusion 
center products should assume a different audience depending on the level of government and departmental setting for whom they are writing.

\section{End-User perceptions of the fusion center of study and its products}

Satisfaction with fusion centers and their products is important for stakeholder buy-in. Table 5 examines end-user satisfaction with analytic products and with the fusion center of study as a whole, by asking whether respondents always open and read products, whether they find analytic products either valuable or extremely valuable, and whether they are either satisfied or very satisfied with their relationship with the fusion center. On the whole, respondents seem to be quite satisfied. For all groups and on all questions, the means are above .50 , indicating that more than half of respondents in each group always open and read products, find the products either valuable or extremely valuable, and are either satisfied or very satisfied with their relationship with the fusion center. Yet despite these promising figures, there are some notable differences between groups.

\section{[ Table 5 Approximately Here ]}

Upper-level personnel are more likely to be satisfied than are either frontline personnel or analysts, with a 62 percent higher likelihood of finding the products valuable and almost twice the likelihood of being satisfied with the fusion center relationship, while frontline personnel are 52 percent less likely to open and read products. These findings suggest that while the center of study is succeeding in meeting the needs of upper-level personnel, they struggle to ensure their products meet the needs of frontline personnel and 
analysts tasked with incorporating that intelligence into daily activities. Fewer noteworthy differences exist among different types of departments, except that respondents from emergency management agencies are 72 percent less likely to open and read products and be satisfied with their relationship with the center of study. While not statistically significant, differences among level of government are insightful. Respondents from local agencies are more likely to open products than state and federal, but they are less likely to find products valuable or be satisfied with their relationship with the center. This seems to suggest that local agencies value receiving intelligence products, but the products from the center and their relationship with the center are not currently meeting their needs. This is particularly so for local agencies in urban areas, which are 54 percent less likely to find analytic products valuable and 85 percent less likely to be satisfied with their relationship with the center.

\section{Discussion}

In 2007, the Homeland Security Council called for an increased use of ILP to improve situational awareness to prevent future terrorist activity and combat crime (Homeland Security Council, 2007). Though ILP can be leveraged without connectivity to a fusion center, many agencies lack the internal capacity (i.e., analysts or disparate data access) to truly utilize an intelligence-led strategy (Carter \& Phillips, 2015; Riley et al., 2005). Thus, the fusion center model is intended to provide, or enhance, the analytic and intelligence capacity of many local agencies. For agencies that do not employ an analyst or have limited access to data systems, fusion centers provide this capability. To date, this assumption that fusion centers enable ILP among law enforcement agencies has gone largely unaddressed 
in the literature. Moreover, this assumption rests on two critically important factors; 1) an agency is aware of and connected to a fusion center to receive intelligence products, and 2) an agency (or end-user) that receives analytic products perceives such products to be actionable or useful for their agency. To this end, the present study utilized survey data from a regional fusion center's end-users to help inform the scant literature regarding the various intelligence needs of law enforcement and non-law enforcement agencies and a fusion center's ability to meet their data-driven needs to enable or enhance ILP. The study produced a number of insightful findings.

First, though upper-level personnel are familiar with the resources available through the fusion center of study, frontline personnel and analysts are disconnected from the center. It seems awareness and connectivity can be improved through informal relationships, training, and further dissemination of products within recipient organizations. Second, urban law enforcement agencies are less likely to be familiar with the fusion center of study and other fusion centers than rural law enforcement agencies. This is somewhat perplexing, and concerning, as urban agencies would seem to have a more pressing operational need to be connected with a fusion center for counter-terrorism and violent crime issues. Though it may be plausible that urban agencies are more likely to have an internal analytic capability and thus perceive less of a reliance on a fusion center, an active partnership with a fusion center in the region can only help to facilitate or improve an ILP approach by connecting the agency to other agencies in the region. There is some evidence that information-sharing breaks down at the county and state levels because of different communications systems, records-management systems, unique to a county 
(Lewandowski \& Nestel, 2016), and thus a fusion center would help connect the agencies within the major urban area.

Third, end-users from health, fire, and EMS had lower likelihoods of knowing about fusion centers and are less likely to forward intelligence products to others. It can be deduced that the "all-hazards" mission of fusion centers may be bolstered if they were able to reach out to these sectors more effectively. Fourth, law enforcement agencies in the sample were more likely to share the information with patrol or investigative patrol in their agency. This is an ideal method of diffusion to increase use of data and potentially develop additional mechanisms for patrol and investigative personnel to push raw information to fusion centers. Relatedly, upper-level personnel appear to understand the importance of shared information and therefore found value in its dissemination. Though this cannot be explored at a more granular level in the current study, it would seem there is a perceived lack of operational value for patrol and analysts.

\section{Limitations}

This study has a few limitation that future research should address. First, the inability use random sampling methods and ensure a higher response rate limit the generalizability of these findings. Future research efforts to overcome privacy concerns perhaps through the use of multi-center studies that can be aggregated - enhance the generalizability of the research into fusion center end users. Second, the lack of appropriate control variables and suitable study design to allow for the elimination of sources of spuriousness does not allow the authors to make causal claims. Future research that does control for sources of spuriousness will also advance our understanding of fusion center 
end users by determining if the patterns uncovered in this study point to relationships that are both substantive and statistically significant.

A salient characteristic of intelligence analysis and resulting products is that endusers find the analytic products to be useful or actionable. The present study attempted to capture end-user perceptions of useful or actionable through three broad measures; the degree to which end-users perceived products to be useful, whether they read products, and whether or not they were satisfied with the fusion center's products (i.e., Table 5). We acknowledge these measures are rather myopic, but were employed in the absence of objective measures to assess such characteristics. As end-users' needs vary dramatically across a range of demographics (agency type, size, resources, location, etc.), a systematic approach to assess the quality of intelligence products has yet to be validated. This is perhaps the next challenge for ILP and fusion center scholars and is addressed in the discussion of future research.

\section{Future Research}

In addition to the unique findings discussed above, the present study identified a number of recommendations for future research to advance the knowledge on fusion center analytic products. First, scholars should consider methods to examine analytic product content and its actionable impact on practice. This may be achieved through a content analysis of intelligence products from fusion centers or perhaps a series of vignette products with varying degrees of operational, strategic, and situational content that can be interpreted by different personnel within an agency. This approach may provide insights 
into the type of data analysis and information that different personnel types perceive to be most useful.

Second, and related to the aforementioned point, researchers should partner with fusion center end-users to observe how analytic products are translated into agency-specific practices. This inquiry should be focused on agency types (i.e., agencies with varying jurisdictions, resources, and crime problems) as well as personnel types (i.e., upper-level, analysts, patrol, and investigators). Data and intelligence needs are likely to have substantive differences across these varying groups.

Lastly, scholars should partner with fusion centers and their end-users to examine nuances of such partnerships. There exists a significant disconnect between fusion centers and partnering organizations despite liaisons from the various agencies within the fusion center. More specifically, scholars should seek to identify how partnerships, or connectivity, is developed between fusion centers and local law enforcement from both perspectives. How and why do local agencies connect with the fusion center and vice versa? There does not exist a standard protocol for creating such information sharing networks and thus additional insight as to the mechanisms that facilitate partnerships should be examined. Such an exploration could yield valuable insights that pertain to the needs of local agencies and fusion centers and expectations of analytic products and data. This insights could potentially serve as a baseline to which the quality of analytic products and satisfaction of relationships can be evaluated against. Furthermore, it would be of great benefit to understand how fusion centers work to cultivate partnerships for information sharing and analysis; what type of analyses are conducted and for what purpose and which partners; how end-users provide information to fusion centers and with what expectation 
for returns; and how fusion centers can leverage other existing data capabilities such as real-time crime centers or mature municipal police department analyst units. Coupled with the findings presented here, each of these recommendations could yield significant progress to better understand the effectiveness of fusion centers to facilitate intelligenceled and data-driven policing strategies. 


\section{References}

Brick, J. M., \& Williams, D. (2013). 'Explaining Rising Nonresponse Rates in CrossSectional Surveys.' The ANNALS of the American Academy of Political and Social Science, 645 (1): 36-59.

Bureau of Justice Assistance. (2012), Reducing Crime through Intelligence-Led Policing. Washington, D.C., available at: https://www.ncirc.gov/documents/public/reducing_crime through ilp.pdf (accessed 6 April 2016).

Burruss, G. W., Giblin, M. J., \& Schafer, J. A. (2010). 'Threatened Globally, Acting Locally: Modeling Law Enforcement Homeland Security Practices.' Justice Quarterly, 27 (1): 77-101.

Carter, D. L. \& Carter, J. G. (2009). 'The Intelligence Fusion Process for State, Local and Tribal Law Enforcement.' Criminal Justice and Behavior, 36 (12): 13231339.

Carter, J. G. (2015), 'Inter-Organizational Relationships and Law Enforcement Information Sharing Post 11 September 2001.' Journal of Crime and Justice, 38(4): $522-542$.

Carter, J. G. (2016). Institutional pressures and isomorphism: The impact on intelligenceled policing adoption. Police Quarterly. DOI: 10.1177/1098611116639536.

Carter, J. G. \& Chermak, S. (2012). 'Evidence-Based Intelligence Practices: Examining the Role of Fusion Centers as a Critical Source of Information.' In Lum, C. and Kennedy, L. (Eds), Evidence-Based Counterterrorism Policy, New York: Springer, pp. 65-88.

Carter, J. G. \& Phillips, S. W. (2015). 'Intelligence-Led Policing and Forces of Organizational Change in the United States.' Policing \& Society, 25 (4): 333-357.

Carter, J. G., Phillips, S.W. \& Gayadeen, S.M. (2014). 'Implementing Intelligence-Led Policing: An Application of Loose-Coupling Theory.' Journal of Criminal Justice, 42 (6): 433-442.

Chermak, S., Carter, J. G., Carter, D. L., McGarrell, E. F., \& Drew, J. (2013). 'Law Enforcement's Information Sharing Infrastructure: A National Assessment." Police Quarterly, 16(2): 211-244.

Cooney, M., Rojek, J., \& Kaminski, R. J. (2011). 'An Assessment of the Utility of a State Fusion Center by Law Enforcement Executives and Personnel.' IALEIA Journal, 20: $1-18$. 
Cope, N. (2004). 'Intelligence Led Policing or Policing Led Intelligence?' The British Journal of Criminology, 44(2), 188-203.

Darroch, S., \& Mazerolle, L. (2013). 'Intelligence-Led Policing: A Comparative Analysis of Organizational Factors Influencing Innovation Uptake.' Police Quarterly, 16(1): 3-37.

Fusion Center Guidelines. (2006). Washington, D.C.: U.S. Department of Justice.

Giblin, M. J. (2006). Structural elaboration and institutional isomorphism: The case of crime analysis units. Policing: An International Journal of Police Strategies \& Management, 29(4), 643-664.

Global Intelligence Working Group. (2005). 'Guidelines for Establishing and Operating Fusion Centers at the Local, State, Tribal and Federal Level.' Washington, DC: U.S. Department of Homeland Security. U.S. Department of Justice.

Goldstein, H. (1979). "Improving Policing: A Problem-Oriented Approach." Crime and Delinquency, 25(2):236-258.

Graphia-Joyal, R. (2010). 'Are Fusion Centers Achieving their Intended Purposes? Findings from a Qualitative Study on the Internal Efficacy of State Fusion Centers.' IALEIA Journal, 19: 54-76.

Groff, E.R., Ratcliffe, J.H., Haberman, C.P., Sorg, E.T., Joyce, N., \& Taylor, R.B. (2015). 'Does What Police do at Hot Spots Matter? The Philadelphia Policing Tactics Experiment.' Criminology, 53(1): 23-53.

Homeland Security Council. (2007). 'National Strategy for Homeland Security.' available at https://www.dhs.gov/xlibrary/assets/nat_strat_homelandsecurity_2007.pdf (accessed 20 November 2015).

Innes, M., Fielding, N., \& Cope, N. (2005). 'The Appliance of Science?' The Theory and Practice of Crime Intelligence Analysis.' British Journal of Criminology, 45(1): $39-57$.

Lewandowski, C., \& Carter, J. G. (2014). 'End-User Perceptions of Intelligence Dissemination from a State Fusion Center.' Security Journal, Advanced online publication. DOI:10.1057/sj.2014.38

Lewandowski, C. and Nestel, T. (2016). 'Police Communication at the Local Level: An Exploratory Study.' Journal of Policing, Intelligence and Counter Terrorism, 11 (1): 49-62. 
Ratcliffe, J.H. (2007). 'Integrated Intelligence and Crime Analysis: Enhanced Information Management for Law Enforcement Leaders.' Police Foundation: Washington D.C.

Ratcliffe, J.H. (2016). Intelligence-Led Policing. (2nd Edition). Routledge: London.

Ratcliffe, J. H. and Guidetti, R. (2008). 'State Police Investigative Structure and the Adoption of Intelligence-Led Policing.' Policing: An International Journal of Police Strategies and Management, 31(1): 109-128.

Ratcliffe, J. H., Strang, S. J., and Taylor, JH (2014). 'Assessing the Success Factors of Organized Crime Groups: Intelligence Challenges for Strategic thinking.' Policing: An International Journal of Police Strategies and Management, 37(1): 206-227.

Ratcliffe, J. H., Sorg, E. T., \& Rose, J. W. (2015). 'Intelligence-Led Policing in Honduras: Applying Sleipnir and Social Psychology to Understand Gang Proliferation.' Journal of Police and Criminal Psychology, 30(2): 112-123.

Ratcliffe, J. H., \& Walden, K. (2010). 'State Police and the Fusion Center: A Study of Intelligence Flow to and from the Street”, IALEIA Journal, 19(1): 1-19.

Riley, K. J., Treverton, G. F.,Wilson, J. M., \& Davis, L. M. (2005). State and Local Intelligence in the War on Terrorism, Santa Monica, CA: Rand.

Roberts, A. \& Roberts, J. M., Jr. (2007). 'The Structure of Informal Communication between Police Agencies.' Policing, 30(1): 93-107.

Rollins, J. (2008, January). 'Fusion Centers: Issues and Options for Congress", Washington, D.C.: Congressional Research Service. Report ADA482006.

Saari, S. C. (2010), Fusion Centers: Securing America's Heartland from Threats. Master's thesis, Naval Postgraduate School, Monterey, CA.

Sanders, C.B., Weston, C., \& Schott, D. (2015). "Police innovations, 'secret squirrels', and accountability: Empirically studying intelligence-led policing in Canada." British Journal of Criminology, 55(4): 711-729.

Santos, R. B. (2014). 'The Effectiveness of Crime Analysis for Crime Reduction: Cure or Diagnosis?' Journal of Contemporary Criminal Justice, 30(2): 147-168.

Sheptycki, J. (2004). "Organizational pathologies in police intelligence systems: Some contributions to the lexicon of intelligence-led policing." The European Journal of Criminology, 1(3): 307-332.

Shih, T. H., \& Fan, X. (2009). 'Comparing Response Rates in E-mail and Paper Surveys: A Meta-analysis.' Educational Research Review, 4 (1): 26-40. 
Taylor, B., Kowalyk, A., \& Boba, R. (2007). 'The Integration of Crime Analysis into Law Enforcement Agencies.' Police Quarterly, 10(2), 154-169.

U.S. Department of Homeland Security. (2005). Intelligence and Information Sharing Initiative: Homeland Security Intelligence and Information Fusion, Washington, D.C., available at: https://www.dhs.gov/xlibrary/assets/HSAC_HSIntelInfoFusion_Apr05.pdf (accessed 18 October, 2016)

U.S. Department of Homeland Security. (2014). '2013 Fusion Center Assessment.' Final Report. Washington, DC.

U.S. Department of Homeland Security. (2015). '2014 National Network of Fusion Center.' Final Report. Washington, DC, Available at: https://www.dhs.gov/publication/2014-fusion-center-assessment (accessed 14 January 2016).

U.S. Department of Homeland Security. "National Network of Fusion Centers Fact Sheet". Washington, DC. Available at: https://www.dhs.gov/national-network-fusioncenters-fact-sheet (accessed 25 October 2016).

U.S. Governmental Accountability Office. (2010). 'Information Sharing: Federal Agencies Are Helping Fusion Centers Build and Sustain Capabilities and Protect Privacy, but Could Better Measure Results.' Washington, DC. Report to Congressional Requesters. Report GAO-10-972.

US House of Representatives. (2013). 'Majority Staff Report on the National Network of Fusion Centers.' Washington, DC: Committee on Homeland Security.

Weiss, A. (1998). 'Informal Information Sharing Among Police Agencies.' National Institute of Justice. U.S. Department of Justice. Washington, DC. FS 000233. 
Table 1. End-User Sample Descriptives

Percent (n)

Position within Organization $(n=341)$

Upper-level

$42.2 \%(144)$

Mid-level

$25.2 \%(86)$

Frontline

$15.0 \%(51)$

Analyst

$8.5 \%(29)$

Departmental Focus $(n=339)$

Law Enforcement $\quad 63.7 \%$ (216)

Private Sector $\quad 12.1 \%(41)$

Health, Fire, and EMS $\quad 8.0 \%(27)$

Emergency Management $\quad 7.1 \%$ (24)

Level of Jurisdiction $(n=216)$

Local

$73.2 \%(158)$

State

$8.8 \%(19)$

Federal

$9.3 \%(20)$

Tribal

$0.9 \%(2)$

Departmental Setting $(n=158)$

Urban

$55.7 \%(88)$

Rural/Suburban

$38.6 \%(61)$ 
Table 2: End-User Connectivity with Fusion Centers

\begin{tabular}{|c|c|c|c|c|}
\hline & $\begin{array}{l}\text { Aware of Fusion Centers } \\
\text { Prior to Learning of This } \\
\text { Center }\end{array}$ & $\begin{array}{l}\text { Also Receive Products from Other } \\
\text { Fusion Centers }\end{array}$ & $\begin{array}{l}\text { Familiar with Fusion Center } \\
\text { Resources }\end{array}$ & $\begin{array}{c}\text { Know How to Contact Fusion } \\
\text { Center }\end{array}$ \\
\hline & Mean (S.D.) [O.R.] Coef & Mean (S.D.) [O.R.] Coef & Mean (S.D.) [O.R.] Coef & Mean (S.D.) [O.R.] Coef \\
\hline Position within Organization & $(n=339)$ & $(n=336)$ & $(n=341)$ & $(n=337)$ \\
\hline Upper-level & $0.87(0.34)[1.52] 0.42$ & $0.64(0.48)[1.00] 0.00$ & $0.73(0.45)[1.80] 0.59^{*}$ & $0.80(0.40)[0.87]-0.14$ \\
\hline Frontline & $0.78(0.42)[0.65]-0.42$ & $0.71(0.46)[1.42] 0.35$ & $0.53(0.50)[0.54]-0.62 *$ & $0.80(0.40)[0.93]-0.08$ \\
\hline Analyst & $0.89(0.31)[1.58] 0.58$ & $0.72(0.45)[1.53] 0.42$ & $0.41(0.50)[0.34]-1.09 * *$ & $0.79(0.42)[0.85]-0.17$ \\
\hline Departmental Focus & $(\mathrm{n}=337)$ & $(n=335)$ & $(\mathrm{n}=339)$ & $(n=335)$ \\
\hline Law Enforcement Agencies & $0.83(0.37)[0.99]-0.01$ & $0.69(0.46)[1.77] 0.57 *$ & $0.69(0.47)[1.44] 0.37$ & $0.84(0.36)[1.92] 0.65^{*}$ \\
\hline Private Sector Agencies & $0.85(0.37)[1.11] 0.10$ & $0.58(0.50)[0.74]-0.31$ & $0.68(0.47)[1.15] 0.14$ & $0.69(0.47)[0.48]-0.73$ \\
\hline Health, Fire, and EMS & $0.67(0.48)[0.36]-1.02 *$ & $0.31(0.47)[0.22]-1.50 * *$ & $0.52(0.51)[0.54]-0.62$ & $0.73(0.45)[0.61]-0.49$ \\
\hline Emergency Management & $0.88(0.34)[1.42] 0.36$ & $0.58(0.50)[0.78]-0.25$ & $0.46(0.51)[0.42]-0.87^{*}$ & $0.63(0.49)[0.36]-1.03 *$ \\
\hline Level of Jurisdiction & $(\mathrm{n}=216)$ & $(n=214)$ & $(n=216)$ & $(\mathrm{n}=215)$ \\
\hline Local & $0.81(0.39)[0.49]-0.71$ & $0.64(0.49)[0.27]-1.30 * *$ & $0.69(0.48)[0.61]-0.49$ & $0.82(0.38)[0.43]-0.83$ \\
\hline State & $0.84(0.37)[1.07] 0.71$ & $0.84(0.37)[2.61] 0.96$ & $0.68(0.48)[1.00]-0.00$ & $0.84(0.37)[0.96]-0.04$ \\
\hline Federal & $0.95(0.22)[4.13] 1.41$ & $0.95(0.22)[9.80] 2.28^{*}$ & $0.75(0.44)[1.42] 0.35$ & $0.90(0.31)[1.70] 0.53$ \\
\hline Departmental Setting & $(\mathrm{n}=158)$ & $(\mathrm{n}=157)$ & $(\mathrm{n}=158)$ & $(\mathrm{n}=157)$ \\
\hline Urban & $0.75(0.44)[0.39]-0.95^{*}$ & $0.48(0.50)[0.21]-1.55^{* * *}$ & $0.55(0.51)[0.30]-1.20 * *$ & $0.76(0.43)[0.35]-1.05 *$ \\
\hline Rural/Suburban & $0.89(0.32)[2.40] 0.88$ & $0.80(0.40)[3.76] 1.32 * *$ & $0.82(0.39)[3.62] 1.29 * *$ & $0.89(0.32)[2.16] 0.77$ \\
\hline
\end{tabular}

Note: The reference group for each statistic are those that responded in the affirmative (Yes) to each item.

$* \mathrm{p}<.05, * * \mathrm{p}<.01, * * * \mathrm{p}<.001$ 
Table 3: Became Aware of Fusion Center of Study

\begin{tabular}{llllll}
\hline & Work Listserv & Word of Mouth & DHS & Training Course & Supervisor \\
\hline Position within Organization $(n=341)$ & & & & & \\
Upper-level & $0.21(0.41)$ & $0.16(0.37)$ & $0.17(0.38)$ & $0.20(0.40)$ & $0.01(0.12)$ \\
Frontline & $0.22(0.42)$ & $0.27(0.45)$ & $0.22(0.42)$ & $0.12(0.33)$ & $0.14(0.35)$ \\
Analyst & $0.14(0.35)$ & $0.10(0.31)$ & $0.14(0.35)$ & $0.24(0.44)$ & $0.14(0.35)$ \\
Departmental focus $(n=339)$ & & & & & \\
Law Enforcement Agencies & $0.23(0.42)$ & $0.22(0.42)$ & $0.14(0.35)$ & $0.19(0.40)$ & $0.08(0.27)$ \\
Private Sector Agencies & $0.12(0.33)$ & $0.05(0.22)$ & $0.37(0.49)$ & $0.12(0.33)$ & $0.02(0.16)$ \\
Health, Fire, and EMS & $0.15(0.36)$ & $0.15(0.36)$ & $0.22(0.42)$ & $0.30(0.47)$ & $0.15(0.36)$ \\
Emergency Management & $0.17(0.38)$ & $0.21(0.41)$ & $0.17(0.38)$ & $0.08(0.28)$ & $0.04(0.20)$ \\
Level of Jurisdiction $(n=216)$ & & & & & \\
Local & $0.23(0.42)$ & $0.24(0.43)$ & $0.09(0.29)$ & $0.22(0.41)$ & $0.08(0.28)$ \\
State & $0.26(0.45)$ & $0.21(0.42)$ & $0.50(0.23)$ & $0.21(0.42)$ & $0.16(0.37)$ \\
Federal & $0.25(0.44)$ & $0.15(0.37)$ & $0.45(0.51)$ & $0.05(0.22)$ & $0.05(0.22)$ \\
Departmental Setting $(n=158)$ & & & & & \\
Urban & $0.18(0.39)$ & $0.25(0.44)$ & $0.09(0.30)$ & $0.20(0.41)$ & $0.11(0.32)$ \\
Rural/Suburban & $0.28(0.45)$ & $0.26(0.44)$ & $0.08(0.28)$ & $0.26(0.44)$ & $0.02(0.13)$ \\
\hline
\end{tabular}


Table 4: End-User Dissemination of Fusion Center Products

\begin{tabular}{|c|c|c|c|c|}
\hline & $\begin{array}{l}\text { All people in the department } \\
\text { are made aware of } \\
\text { information }\end{array}$ & $\begin{array}{l}\text { Investigative personnel are } \\
\text { made aware of the } \\
\text { information }\end{array}$ & $\begin{array}{l}\text { Patrol personnel are made } \\
\text { aware of the information }\end{array}$ & $\begin{array}{l}\text { Forward Fusion Center } \\
\text { Products to Others }\end{array}$ \\
\hline & Mean (S.D.) [O.R.] Coef & Mean (S.D.) [O.R.] Coef & Mean (S.D.) [O.R.] Coef & Mean (S.D.) [O.R.] Coef \\
\hline Departmental Focus & $(\mathrm{n}=339)$ & $(\mathrm{n}=339)$ & $(n=339)$ & $(\mathrm{n}=337)$ \\
\hline Law Enforcement Agencies & $0.55(0.50)$ [2.09] $0.74 * *$ & $0.59(0.49)[5.89] 1.77 * * *$ & $0.52(0.50)[3.56] 1.27 * * *$ & $0.61(0.49)[1.41] 0.34$ \\
\hline Private Sector Agencies & $0.41(0.50)[0.74]-0.30$ & $0.29(0.46)[0.47]-0.75^{*}$ & $0.24(0.43)[0.41]-0.90^{*}$ & $0.58(0.50)[1.02] 0.02$ \\
\hline Health, Fire, and EMS & $0.30(0.47)[0.43]-0.85$ & $0.00(0.00)$ & $0.07(0.27)[0.10]-2.32 * *$ & $0.52(0.51)[0.76]-0.28$ \\
\hline Emergency Management & $0.21(0.41)[0.26]-1.34 * *$ & $0.17(0.38)[0.23]-1.48^{* *}$ & $0.29(0.46)[0.55]-0.60$ & $0.50(0.51)[0.70]-0.36$ \\
\hline Level of Jurisdiction & $(n=216)$ & $(\mathrm{n}=216)$ & $(\mathrm{n}=216)$ & $(n=214)$ \\
\hline Local & $0.57(0.50)[1.42] 0.35$ & $0.54(0.50)[0.50]-0.70^{*}$ & $0.51(0.50)[0.85]-0.16$ & $0.63(0.48)[1.33] 0.29$ \\
\hline State & $0.47(0.51)[0.73]-0.32$ & $0.74(0.45)[2.08] 0.73$ & $0.58(0.51)[1.28] 0.25$ & $0.68(0.48)[1.41] 0.35$ \\
\hline Federal & $0.25(0.44)[0.24]-1.41^{* *}$ & $0.75(0.44)[2.25] 0.81$ & $0.35(0.49)[0.46]-0.78$ & $0.53(0.51)[0.68]-0.39$ \\
\hline Departmental Setting & $(\mathrm{n}=158)$ & $(\mathrm{n}=158)$ & $(\mathrm{n}=158)$ & $(\mathrm{n}=157)$ \\
\hline Urban & $0.50(0.50)[0.52]-0.65^{*}$ & $0.51(0.50)[0.74]-0.30$ & $0.49(0.50)[0.80]-0.22$ & $0.50(0.50)[0.25]-1.37 * * *$ \\
\hline Rural/Suburban & $0.69(0.47)[2.26] \quad 0.81^{*}$ & $0.57(0.50)[1.21] 0.19$ & $0.57(0.50)[1.49] \quad 0.40$ & $0.85(0.36)[5.78] 1.76^{* * *}$ \\
\hline
\end{tabular}

Note: The reference group for each statistic are those that responded in the affirmative (Yes) to each item.

${ }^{*} \mathrm{p}<.05,{ }^{* *} \mathrm{p}<.01, * * * \mathrm{p}<.001$ 
Table 5: End-User Perceptions of the Fusion Center of Study and its Products

\begin{tabular}{|c|c|c|c|}
\hline & $\begin{array}{l}\text { Always Open and } \\
\text { Read Products }\end{array}$ & $\begin{array}{l}\text { Found the Fusion Center } \\
\text { Products Useful }\end{array}$ & $\begin{array}{l}\text { Satisfied with Relationship } \\
\text { with the Fusion Center }\end{array}$ \\
\hline & Mean (S.D.) [O.R.] Coef & Mean (S.D.) [O.R.] Coef & Mean (S.D.) [O.R.] Coef \\
\hline Position within Organization & $(\mathrm{n}=341)$ & $(\mathrm{n}=339)$ & $(\mathrm{n}=325)$ \\
\hline Upper-level & $0.83(0.38)[1.14] 0.13$ & $0.95(0.22)[1.27] 0.24$ & $0.96(0.20)[2.93] 1.08^{*}$ \\
\hline Frontline & $0.71(0.46)[0.48]-0.74 *$ & $1.00(0.00)$ & $0.90(0.30)[0.82]-0.20$ \\
\hline Analyst & $0.86(0.35)[1.46] 0.38$ & $0.93(0.26)[0.78]-0.24$ & $0.89(0.31)[0.77]-0.27$ \\
\hline Departmental Focus & $(\mathrm{n}=339)$ & $(\mathrm{n}=337)$ & $(\mathrm{n}=323)$ \\
\hline Law Enforcement Agencies & $0.81(0.39)[0.96]-0.04$ & $0.97(0.17)[4.10] 1.41 * *$ & $0.91(0.28)[0.98]-0.02$ \\
\hline Private Sector Agencies & $0.93(0.26)[3.12] 1.14$ & $0.95(0.22)[1.19] 0.17$ & $0.93(0.27)[1.20] 0.18$ \\
\hline Health, Fire, and EMS & $0.89(0.32)[1.87] 0.62$ & $0.89(0.32)[0.44]-0.83$ & $0.92(0.27)[1.15] 0.14$ \\
\hline Emergency Management & $0.58(0.50)[0.28]-1.28^{* *}$ & $0.79(0.41)[0.18]-1.72 * *$ & $0.77(0.43)[0.28]-1.27^{*}$ \\
\hline Level of Jurisdiction & $(n=216)$ & $(\mathrm{n}=214)$ & $(\mathrm{n}=206)$ \\
\hline Local & $0.82(0.38)[1.21] 0.19$ & $0.97(0.16)[1.36] 0.31$ & $0.90(0.30)[0.50]-0.70$ \\
\hline State & $0.79(0.42)[0.84]-0.18$ & $1.00(0.00)$ & $0.95(0.23)[1.80] 0.59$ \\
\hline Federal & $0.65(0.49)[0.38]-0.98$ & $1.00(0.00)$ & $0.90(0.31)[0.85]-0.17$ \\
\hline Departmental Setting & $(\mathrm{n}=158)$ & $(\mathrm{n}=156)$ & $(n=149)$ \\
\hline Urban & $0.81(0.40)[0.78]-0.25$ & $0.97(0.18)[0.41]-0.89$ & $0.84(0.37)[0.15]-1.84^{*}$ \\
\hline Rural/Suburban & $0.87(0.34)[1.72] 0.54$ & $1.00(0.00)$ & $1.00(0.00)$ \\
\hline
\end{tabular}

Note: The reference group for each statistic are those that responded in the affirmative (Yes) to each item.

$* \mathrm{p}<.05, * * \mathrm{p}<.01, * * * \mathrm{p}<.001$ 